\title{
Canadian Virtual Health Library / Bibliothèque virtuelle canadienne de la santé (CVHL/BVCS)
}

\section{CVHL/BVCS - now coast to coast!}

At the Board meeting on November 23, we were delighted to hear that the Electronic Health Library of British Columbia (eHLBC) and the Health Knowledge Network (HKN) (Alberta) have agreed in principle to participate in CVHL/BVCS. This makes CVHL/BVCS truly representative from coast to coast to coast - all across Canada!

Much of the work of the Board of Directors has been devoted to setting up the necessary structures for the CVHL/BVCS. At the four Board meetings held since the last report (June 22, July 24, September 19, and November 23) several start-up issues have been settled. For instance, the CVHL/BVCS Board has decided to use only the English and French acronym, CVHL/BVCS, rather than one or the other, in all of its publications and promotional materials, print and electronic.

Director insurance for Board Members was purchased from Lombard Canada Ltd. This puts the CVHL/BVCS Board in line with the current practice of other boards, including that of the CHLA/ABSC Board. A nominating committee has been struck and that group will be looking at filling positions in the future for a management committee and for a finance and audit committee.

A fundraising policy, a conflict of interest policy, and an academic publications policy have all been adopted. The next policy to be developed is one on commercialization, followed by a data policy. Remaining policies will be developed on an ad hoc basis.

Jim Henderson is the Treasurer and the Board has been presented with financial tracking on a quarterly basis.

The Board has spent much of its time on fundraising initiatives. All Board members have been working in their own geographic areas to find financial support. A priority of the Board is raising enough money or in-kind support to fund operations and the portal. The Chair of the Board, Adalsteinn Brown, will be requesting a meeting with the Conference of Deputy Ministers of Health with an appeal for funding.

Both Board members and CVHL/BVCS staff have been approached by groups who are very interested in being part of the CVHL/BVCS. For instance, Canadian Health Services Research Foundation (CHSRF), the Canadian Institute for Health Information (CIHI), and the Canadian
Partnership Against Cancer (CPAC) are interested in supplying content for the CVHL/BVCS web site, and would also like to join CVHL/BVCS as Network subscribers. Because of this interest, the Board has recognized that the CVHL/BVCS is being seen as more than just a licensing consortium. A Working Group has been formed to investigate how such groups can be included as partners.

Two PowerPoint slide presentations have been developed by CVHL/BVCS staff to support marketing efforts. The Value Proposition presentation will be used for fundraising and the Stakeholder Update presentation will be used to update those who were supporters in previous phases of the project. Jennifer Bayne will be sending the Stakeholder Update presentation to those groups who wrote letters of support in the initial phases of CVHL/BVCS. This is an opportunity to give those early supporters an update on events.

The Board needs volunteers to help in developing the CVHL/BVCS database. For further information please contact any of the Cataloguing Group members (Dean Giustini, Tom Flemming, Natalie Clairoux, Gurvinder Batra, Yongtao Lin, and Tracy Daley), Jennifer Bayne (Jennifer.bayne@knowledge-able.com) or the CVHL/ BVCS at admin@cvhl.ca.

Submitted by: Penny Logan and Rebecca Raworth, CHLA/ABSC representatives on the CVHL/BVCS Board of Directors.

\author{
Penny Logan \\ Manager Library Services \\ Capital Health \\ 1796 Summer St. \#2212 \\ Halifax, NS B3H 3 A7 \\ 902-473-4383 \\ Fax 902-473-8651 \\ E-mail:penny.logan@cdha.nshealth.ca
}

Rebecca Raworth

Island Medical Program Librarian

University of Victoria Libraries

PO Box 1800 STN CSC

Victoria, BC V8W $3 H 5$

250-721-8269

Fax: 250-721-8235

E-mail:raworthr@uvic.ca 